\title{
Blastocystis subtypes in irritable bowel syndrome and inflammatory bowel disease in Ankara, Turkey
}

\author{
Funda Dogruman-Al ${ }^{1 /+}$, Semra Kustimur ${ }^{1}$, Hisao Yoshikawa ${ }^{2}$, Candan Tuncer ${ }^{3}$, Zahide Simsek ${ }^{3}$, \\ Mehmet Tanyuksel $^{4}$, Engin Araz ${ }^{4}$, Kenneth Boorom ${ }^{5}$
}

${ }^{1}$ Department of Microbiology and Clinical Microbiology ${ }^{3}$ Department of Internal Medicine, Section of Gastroenterology, Gazi University School of Medicine, 06500 Besevler, Ankara, Turkey ${ }^{2}$ Department of Biological Sciences, Nara Women's University, Faculty of Science, Kitauoya-Nishimachi, Nara, Japan ${ }^{4}$ Division of Medical Parasitology, Department of Microbiology and Clinical Microbiology, Gulhane Military Medical Academy, Etlik, Ankara, Turkey ${ }^{5}$ Blastocystis Research Foundation, Philomath, Oregon, USA

Blastocystis infection has been reported to be associated with irritable bowel syndrome (IBS), inflammatory bowel disease (IBD) and chronic diarrhoea. The availability of data on the subtypes of Blastocystis found in these patient groups would be of interest in understanding the significance of Blastocystis infection in chronic illness. In this study, we identify Blastocystis subtypes found in patients presenting with IBS, IBD, chronic diarrhoea and asymptomatic patients in Ankara, Turkey. Blastocystis was detected in 11 symptomatic patients by microscopy and 19 by stool culture. Stool culture was more sensitive than microscopy in identifying Blastocystis. Using standard nomenclature adopted in 2007, Blastocystis sp. subtype 3 was the most common in all groups, followed by Blastocystis sp. subtype 2. Identical subtypes of Blastocystis are found in patients with IBS, IBD and chronic diarrhoea. These particular subtypes show low host specificity and are carried by humans and some farm animals. The subtypes of Blastocystis that are commonly found in rodents and certain wild birds were not found in these patients. We suggest a model in which the severity of enteric protozoan infection may be mediated by host factors.

Key words: Blastocystis hominis - subtyping - chronic diarrhoea - irritable bowel syndrome - inflammatory bowel disease - pathogenicity

Blastocystis is a prevalent enteric protist that can be found in patients with or without gastrointestinal symptoms. Some of the symptoms associated with Blastocystis infection include abdominal pain (88\%), constipation $(32 \%)$, diarrhoea $(23 \%)$, alternating diarrhea and constipation (15\%) and others (Qadri et al. 1989). Irritable bowel syndrome (IBS) is a highly prevalent gastrointestinal disorder of unknown cause with symptoms that include abdominal pain $(100 \%)$, constipation (24\%), diarrhoea $(25 \%)$ and alternating diarrhoea and constipation (46\%) (Wilson et al. 2004). Inflammatory bowel disease (IBD) is a disease of unknown cause associated with diarrhoea and colonic lesions that are identified by endoscopy (Sands 2006, Su \& Lictenstein 2006).

Studies have shown that Blastocystis infection can be associated with IBS (Yakoob et al. 2004, Windsor 2007), IBD (Nagler et al. 1993, al-Tawil et al. 1994) and chronic diarrhoea (Doyle et al. 1990). Traditionally, Blastocystis isolates from humans have been identified as Blastocystis hominis, however phylogenetic analysis has suggested that multiple subtypes of Blastocystis can

Financial support: Gazi University Unit of Scientific Research Projects (Project 01/2005-39), Grant-in-Aid for Scientific Research to HY (B-17406007), The Scientific and Technological Research Council of Turkey (281-2245/2007)

+ Corresponding author: alfunda@gazi.edu.tr

Received 2 December 2008

Accepted 11 May 2009 infect humans and that they possess biomedically relevant differences (Boorom et al. 2008). The availability of data on the subtypes of Blastocystis found in these patient groups would be of interest in understanding the significance of Blastocystis infection in chronic illness. In this study, we identify Blastocystis subtypes found in patients presenting with IBS, IBD and chronic diarrhoea in Ankara, Turkey.

\section{PATIENTS, MATERIALS AND METHODS}

Sources and isolation of Blastocystis - Symptomatic patients were classified as follows: (i) patients with chronic diarrhoea: individuals with diarrhoea present for two or more weeks; (ii) patients with IBD: individuals diagnosed with ulcerative colitis or Crohn's disease by sigmoidoscopy, barium enema, colonoscopy and laboratory analysis (Sands 2006, Su \& Lictenstein 2006) and (iii) patients with IBS: individuals meeting Rome criteria II who attended the gastroenterology clinic at the Gazi University School of Medicine (Talley 2006).

Faecal specimens were obtained from patients using routine procedures at the laboratory of parasitology at Gazi University from September 2005-July 2007. Faecal samples were collected from 105 symptomatic patients (female/male: 58/47, age: $43.8 \pm 4.21$ ) and 96 asymptomatic controls (female/male: 53/43, age: $45.4 \pm 3.5$ ). All stool samples were evaluated through native-lugol, trichrome and Kinyoun's acid fast-staining methods. Stool samples containing other parasites were excluded from our study. The faecal specimens were cultured in Ringer's solution containing $10 \%$ horse serum and $0.05 \%$ asparagine at $37^{\circ} \mathrm{C}$. Screening for Blastocystis organisms was performed on 3-4-day-old cultures by 
standard light microscopy. When vacuolar or granular forms of Blastocystis were observed, they were subcultured in fresh medium (Yoshikawa et al. 2004). After one or two subcultures, Blastocystis suspensions were centrifuged at $12,000 \mathrm{~g}$ for $1 \mathrm{~min}$. The resulting pellet was stored at $-20^{\circ} \mathrm{C}$ until the DNA was extracted.

Genomic DNA preparation - Genomic DNA from Blastocystis was extracted using the DNAzol kit (Invitrogen Life Technologies, Carlsbad CA, USA) following the manufacturer's instructions.

Subtyping by PCR with STS primers - Seven standardised subtype-specific STS primers were used, namely SB83 (351 bp) for subtype 1, SB340 (704 bp) for subtype 2, SB227 (526 bp) for subtype 3, SB337 (487 bp) for subtype 4, SB336 (317 bp) for subtype 5, SB332 (338 bp) for subtype 6 and SB155 (650 bp) for subtype 7 (Yoshikawa et al. 2003a). PCR conditions and electrophoresis of PCR products was performed as previously described (Yoshikawa et al. 2000). We adhered to the recently proposed classification nomenclature, in which Blastocystis $\mathrm{sp}$. subtypes are identified as $\mathrm{n}$, where $\mathrm{n}$ is a designation developed through phylogenetic classification by small-subunit ribosomal DNA analysis (Stensvold et al. 2007). Other studies have used differing classification systems, which can be converted to the standard system in some cases.

Blastocystis strains Nand II, HJ96-1, HV93-13, RN94-9, SY94-3, HJ96AS-1 and B were used as positive controls to verify correct subtyping of Blastocystis sp. subtypes 1-7 (Yoshikawa et al. 1998, 2000, 2003b).

Statistical analysis - Statistical analysis was performed using the Statistical Package for the Social Sciences 13.0 software package. Chi-square analysis was used to compare the sensitivity of detection between the culture method and the direct microscopic examination of stool. A probability value of less than 0.05 was considered statistically significant.

Ethics - The study was approved by the Gazi University, School of Medicine Local Ethical Committee.

\section{RESULTS}

Table I summarises the Blastocystis subtypes isolated from the different patient groups. Table II provides detailed information on the symptomatic status of the patients from whom Blastocystis was isolated. By direct microscopy, we detected Blastocystis in 11 symptomatic patients and eight asymptomatic patients. Using the culture method, we detected Blastocystis in eight additional symptomatic patients and eight additional asymptomatic patients. The culture method was found to be more sensitive in the detection of Blastocystis than direct microscopic stool examination $\left(\mathrm{X}^{2}=99.522, \mathrm{df}=1, \mathrm{p}<0.001\right)$. Compared to the culture method, direct microscopy had a sensitivity of $57.9 \%$ in symptomatic cases and $50 \%$ in asymptomatic cases.

When 35 isolates were screened by PCR amplification with the STS primers, subtypes 2 and 3 were detected in all patients groups (Table I, Fig.1). Subtype $1(6.2 \%)$ was only detected among the asymptomatic group. Mixed infections were detected in the asymptomatic (subtypes 1 $1+2$ ) (Fig.2) and chronic diarrhoea groups (subtypes $2+3$ ).

\section{DISCUSSION}

In this study, we identified Blastocystis subtypes 2 and 3 to be associated with chronic infection in both symptomatic and asymptomatic individuals. These results are similar to those reported in a study of a French population, which found most human infections to be associated with Blastocystis subtypes 1-3 (L Souppart et al. 2009, unpublished observations). Zoonotic subtypes, such as those found in rats and wild birds (subtypes 4, $6,7)$, have not been commonly found in patients with chronic infections (Boorom et al. 2008). A prior study has found that subtype 2 is more frequently associated with asymptomatic infection (Dogruman-Al et al. 2008). However, researchers have not consistently reported a relationship similar to that seen in Entamoeba histolytica/dispar, in which virtually all carriers of a particular protozoan subtype are asymptomatic (Stanley 2003).

The lack of a correlation between symptoms and subtypes suggests that host factors may play a strong role in the expression of symptoms. A similar phenomenon has been observed in E. histolytica, where the identical strain can produce asymptomatic infection in one individual and severe illness in another (Stanley 2003). Host genetic factors that can enhance the production of infection-fighting proteins, such as TNF- $\alpha$ may lead to the expression of symptoms in E. histolytica infection (Stanley 2003). A similar pattern is observed in IBS, in which patients who produce

TABLE I

Blastocystis genotypes from patients groups

\begin{tabular}{lcccc}
\hline Patient group & Subtype 1 & Subtype 2 & Subtype 3 & Co-infections \\
\hline Asymptomatic & 1 & 2 & 11 & 2 co-infections of subtypes 1 and 2 \\
IBS & 0 & 2 & 3 & 0 \\
IBD & 0 & 2 & 5 & 0 \\
Chronic diarrhea & 0 & 4 & 2 & 1 co-infection of subtypes 2 and 3 \\
Total & 1 & 10 & 21 & 3 \\
\hline
\end{tabular}

IBD: inflammatory bowel disease; IBS: irritable bowel syndrome. 
TABLE II

Details on patients from whom Blastocystis was isolated

\begin{tabular}{lccc}
\hline Patient & Age/sex & Diagnosis & Subtype \\
\hline 1 & $32 / \mathrm{M}$ & $\mathrm{CD}$ & 2 \\
2 & $46 / \mathrm{M}$ & $\mathrm{CD}$ & 2,3 \\
3 & $37 / \mathrm{F}$ & $\mathrm{CD}$ & 2 \\
4 & $19 / \mathrm{F}$ & $\mathrm{CD}$ & 3 \\
5 & $43 / \mathrm{M}$ & $\mathrm{CD}$ & 3 \\
6 & $53 / \mathrm{M}$ & $\mathrm{CD}$ & 2 \\
7 & $36 / \mathrm{F}$ & $\mathrm{CD}$ & 2 \\
8 & $46 / \mathrm{M}$ & IBS & 2 \\
9 & $40 / \mathrm{F}$ & IBS & 2 \\
10 & $58 / \mathrm{F}$ & IBS & 3 \\
11 & $26 / \mathrm{M}$ & IBS & 3 \\
12 & $50 / \mathrm{M}$ & IBS & 3 \\
13 & $41 / \mathrm{M}$ & IBD & 3 \\
14 & $47 / \mathrm{M}$ & IBD & 3 \\
15 & $52 / \mathrm{F}$ & IBD & 3 \\
16 & $58 / \mathrm{M}$ & IBD & 3 \\
17 & $32 / \mathrm{M}$ & IBD & 2 \\
18 & $43 / \mathrm{M}$ & IBD & 2 \\
19 & $40 / \mathrm{F}$ & IBD & 3 \\
\hline
\end{tabular}

CD: chronic diarrhea; IBD: inflammatory bowel disease; IBS: irritable bowel syndrome; F: female; M: male.

high levels of TNF- $\alpha$ and low levels of immunosuppressive IL-10 are over-represented in the IBS population (van der Veek et al. 2005). Studies from Europe and the Middle East have found that approximately $30-40 \%$ of IBS patients are Blastocystis carriers (Boorom et al. 2008).

The genetic diversity present in the human immunological response may allow the prevalence of E. histolytica to reach high levels in apparently healthy populations, confounding observational studies. In Egypt, 21\% of healthy adults are infected with E. histolytica (Stanley 2003). A 1987 study done by one US researcher of a population in San Francisco reported finding no correlation between symptoms and infection with E. histolytica and Giardia (Markell et al. 1984). The same researcher found a similar result in Blastocystis and concluded that it was non-pathogenic (Udkow \& Markell 1993), suggesting the need for an objective method to assess pathogenicity. Animal models exist to study the most common enteric protozoa. Experimental infection of mice and rats with Blastocystis isolates found in humans has been reported to produce illness or death in a number of independent studies (Moe et al. 1997, Yao et al. 2005, Zhang et al. 2006, Hussein et al. 2008).

IBS and IBD are thought of as psychiatric or autoimmune diseases, therefore contemporary studies addressing their pathogenesis are of value. A study of colonic biopsies taken from IBS and IBD patients found that gastrointestinal symptoms in these diseases are a result of serine protease production (Cenac et al. 2007). Serine proteases become neurologically active at high levels,

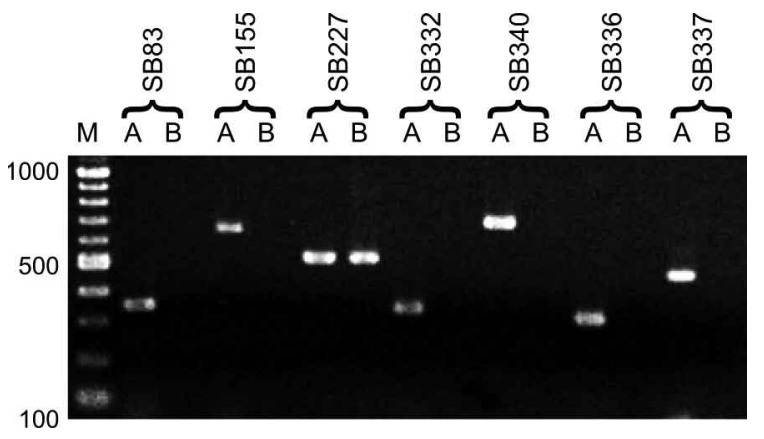

Fig. 1: subtyping DNA analysis of a Blastocystis isolate. The positive control (A) and an isolate from an irritable bowel syndrome patient (B) showed a specific single band of 526 bp amplified with SB227 primer (subtype 3). Lane-M: 100 bp DNA ladder.

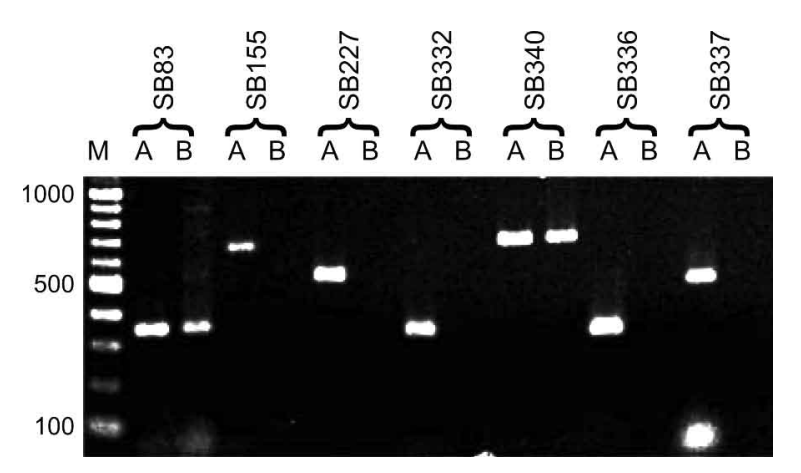

Fig. 2: subtyping DNA analysis of a Blastocystis isolate. The positive control (A) and an isolate from an inflammatory bowel disease patient (B) showed two bands of $351 \mathrm{bp}$ and $704 \mathrm{bp}$ amplified by SB83 and SB340 primers, respectively (subtypes 1 and 2). Lane M: 100 bp DNA ladder.

producing abdominal aches, muscular contractions and widespread pain. These high levels of serine proteases are not found in viral or bacterial enteritis (Gecse et al. 2008). Proteases are produced by protozoa to degrade host immunological factors, such as IgA (Puthia et al. 2005). Secretion of high levels of enteric anti-Blastocystis IgA has been found to be a common factor in all symptomatic, but not asymptomatic, cases of Blastocystis (Mahmoud et al. 2003). This finding suggests that the protozoan does not attack the host, but rather that the host attacks the protozoan and that the disease is a result of the protozoan's defence mechanisms. This theory would explain why some individuals can be carriers of the organism without expressing symptoms and why researchers sometimes find that symptoms appear to be contingent on other health factors (Markell \& Udkow 1986).

The study of Blastocystis may offer a productive avenue for understanding the role of protozoan infection in prevalent unexplained chronic enteric disease, such as IBS and IBD. To facilitate such a study, it is necessary to identify the subtype of Blastocystis present in patients with IBS and IBD and to be able to understand what conditions in the host may contribute to the expression of 
pathogenic behaviour in those subtypes. In this study, we have identified Blastocystis sp. subtypes 2 and 3 in patients with chronic diarrhoea, IBS and IBD. However, Blastocystis sp. subtype 3 was the most commonly found. We suggest a model in which host factors and pathogen factors interact to produce a state of symptomatic infection. A better understanding of the interaction between these factors and the development of reliable techniques for identifying infection will help focus future research efforts. Blastocystis sp. subtype 3 is available from the American Tissue and Culture Collection (ATCC) as ATCC 50587, 50629, 50754 (Jones et al. 2008).

\section{REFERENCES}

al-Tawil YS, Gilger MA, Gopalakrishna GS, Langston C, Bommer KE 1994. Invasive Blastocystis hominis infection in a child. Arch Pediatr Adolesc Med 148: 882-885.

Boorom KF, Smith H, Nimri L, Viscogliosi E, Spanakos G, Parkar U, Li LH, Zhou XN, Ok UZ, Leelayoova S, Jones MS 2008. Oh my aching gut: irritable bowel syndrome, Blastocystis and asymptomatic infection. Parasit Vectors 1: 40.

Cenac N, Andrews CN, Holzhausen M, Chapman K, Cottrell G, Andrade-Gordon P, Steinhoff M, Barbara G, Beck P, Bunnet NW, Sharkey KA, Ferraz JG, Shaffer E, Vergnolle N 2007. Role for protease activity in visceral pain in irritable bowel syndrome. J Clin Invest 117: 636-647.

Dogruman-Al F, Dagci H, Yoshikawa H, Kurt O, Demirel M 2008. A possible link between subtype 2 and asymptomatic infections of Blastocystis hominis. Parasitol Res 103: 685-689.

Doyle PW, Helgason MM, Mathias RG, Proctor EM 1990. Epidemiology and pathogenicity of Blastocystis hominis. J Clin Microbiol 28: $116-121$.

Gecse K, Roka R, Ferrier R, Leveque M, Eutamene H, Cartier C, AitBelgnaoui A, Rosztoczy A, Izbeki F, Fiaramonti J, Wittmann T, Bueno L 2008. Increased faecal serine protease activity in diarrhoeic IBS patients: a colonic lumenal factor impairing colonic permeability and sensitivity. Gut 57: 591-599.

Hussein EM, Hussein AM, Eida MM, Atwa MM 2008. Pathophysiological variability of different genotypes of human Blastocystis hominis Egyptian isolates in experimentally infected rats. Parasitol Res 102: 853-860.

Jones MS, Ganac RD, Hiser G, Hudson NR, Le A, Whipps CM 2008. Detection of Blastocystis from stool samples using real-time PCR. Parasitol Res 103: 551-557.

Mahmoud MS, Saleh WA 2003. Secretory and humoral antibody responses to Blastocystis hominis in symptomatic and asymptomatic human infections. J Egypt Soc Parasitol 33: 13-30.

Markell EK, Havens RF, Kuritsubo RA, Wingerd J 1984. Intestinal protozoa in homosexual men of the San Francisco Bay area: prevalence and correlates of infection. Am J Trop Med Hyg 33: 239-245.

Markell EK, Udkow MP 1986. Blastocystis hominis: pathogen or fellow traveller? Am Trop Med Hyg 35: 1023-1026.

Moe KT, Singh M, Howe J, Ho LC, Tan SW, Chen QX, Ng GC, Yap EH 1997. Experimental Blastocystis hominis infection in laboratory mice. Parasitol Res 83: 319-325.

Nagler J, Brown M, Soave R 1993. Blastocystis hominis in inflammatory bowel disease. J Clin Gastroenterol 16: 109-112.

Puthia MK, Vaithilingam A, Lu J, Tan KS 2005. Degradation of human secretory immunogloulin A by Blastocystis. Parasitol Res 97: 386-389.
Qadri, SM, al-Okaili GA, al-Dayel F 1989. Clinical significance of Blastocystis hominis. J Clin Microbiol 27: 2407-2409.

Sands BE 2006. Crohn's disease. In M Feldman, LS Friedman, LJ Brant, MH Sleisenger, Sleisenger and Fordtran's gastrointestinal and liver disase, Pathophysiology Diagnosis Management, 8th ed., Saunders Elsevier, USA, p. 2459-2490.

Souppart L, Sanciu G, Cian A, Wawrzyniak I, Delbac F, Capron M, Dei-Cas E, Boorom K, Delhaes L, Viscogliosi E 2009. Molecular epidemiology of human Blastocystis isolates in France. Parasitol Res, in press.

Stanley SL Jr 2003. Amoebiasis. Lancet 361: 1025-1034.

Stensvold CR, Suresh GK, Tan KSW, Thompson RCA, Traub RJ, Viscogliosi E, Yoshikawa H, Clark CG 2007. Terminology for Blastocystis subtypes - a consensus. Trends Parasitol 23: 93-96.

Su C, Lictenstein GR 2006. Ulcerative colitis. In M Feldman, LS Friedman, LJ Brant, MH Sleisenger, Sleisenger and Fordtran's gastrointestinal and liver disase. Pathophysiology diagnosis management, 8th ed., Saunders Elsevier, USA, p. 2499-2538.

Talley NJ 2006. Irritabl bowel syndrome. In M Feldman, LS Friedman, LJ Brant, MH Sleisenger, Sleisenger and Fordtran's gastrointestinal and liver disase. Pathophysiology diagnosis management, 8th ed., Saunders Elsevier, USA, p. 2633-2646.

Udkow MP, Markell EK 1993. Blastocystis hominis: prevalence in asymptomatic host. J Infect Dis 168: 242-244.

van der Veek PP, van den Berg M, de Kroon YE, Verspaget HW, Masclee AA 2005. Role of tumor necrosis factor-alpha and interleukin-10 gene polymorphisms in irritable bowel syndrome. $\mathrm{Am} J$ Gastroenterol 100: 2510-2516.

Wilson S, Roberts L, Roalfe A, Bridge P, Singh S 2004. Prevalence of irritable bowel syndrome: a community survey. Br J Gen Pract 54: 495-502.

Windsor JJ 2007. Blastocystis hominis and Dientamoeba fragilis: neglected human protozoa. Br J Biomed Sci 64: 524-527.

Yakoob J, Jafri W, Jafri N, Khan R, Islam M, Beg MA, Zaman V 2004. Irritable bowel syndrome: in search of an etiology: role of Blastocystis hominis. Am J Trop Med Hyg 70: 383-385.

Yao FR, Qiao JY, Zhao Y, Zhang X, Yang JH, Li XQ 2005. Experimental infection of mice with Blastocystis hominis. Zhongguo $J i$ Sheng Chong Xue Yu Ji Sheng Chong Bing Za Zhi 23: 444-448.

Yoshikawa H, Abe N, Iwasawa M, Kitano S, Nagano I, Wu Z, Takahashi Y 2000. Genomic analysis of Blastocystis hominis strains isolated from two long-term health care facilities. J Clin Microbiol 38: 1324-1330.

Yoshikawa H, Abe N, Wu Z 2003a. Genomic polymorphism among Blastocystis isolates and development of PCR-based identification of zoonotic isolates. J Eukaryot Microbiol 50 (Suppl.): 710-711.

Yoshikawa H, Nagano I, Wu Z, Yap EH, Singh M, Takahashi Y 1998. Genomic polymorphism among Blastocystis hominis strains and development of subtype-specific diagnostic primers. Mol Cell Probes 12: 153-159.

Yoshikawa H, Wu Z, Kimata I, Iseki M, Ali IK, Hossain MB, Zaman V, Haque R, Takahashi Y 2004. Polymerase chain reaction-based genotype classification among human Blastocystis hominis populations isolated from different countries. Parasitol Res 92: 22-29.

Yoshikawa H, Wu Z, Nagano I, Takahashi Y 2003b. Molecular comparative studies among Blastocystis isolates obtained from humans and animals. J Parasitol 89: 585-594.

Zhang HW, Li W, Yap QY, He LJ, Su YP 2006. Impact of Blastocystis hominis infection on ultrastructure of intestinal mucosa in mice. Zhongguo Ji Sheng Chong Xue Yu Ji Sheng Chong Bing Za Zhi 24: $187-191$ 